\title{
The LsrB Protein Is Required for Agrobacterium tumefaciens Interaction with Host Plants
}

\author{
Guirong Tang, ${ }^{1,2}$ Qiong Li, ${ }^{1}$ Shenghui Xing, ${ }^{1}$ Ningning Li, ${ }^{1}$ Zheng Tang, ${ }^{1}$ Liangliang Yu, ${ }^{1}$ Junhui Yan, ${ }^{1}$ \\ Xuan $\mathrm{Li}^{3}$ and $\mathrm{Li} \mathrm{Luo}^{1,+}$ \\ ${ }^{1}$ Shanghai Key Laboratory of Bio-energy Crops, Center of Plant Science, School of Life Sciences, Shanghai University, \\ Shanghai 200444, China; ${ }^{2}$ School of Communication \& Information Engineering, Shanghai University; and ${ }^{3}$ Key Laboratory of \\ Synthetic Biology, Institute of Plant Physiology and Ecology, Shanghai Institutes for Biological Sciences, Chinese Academy of \\ Sciences, Shanghai 200032, China
}

Accepted 8 March 2018.

\begin{abstract}
Agrobacterium tumefaciens infects and causes crown galls in dicot plants by transferring T-DNA from the Ti plasmid to the host plant via a type IV secretion system. This process requires appropriate environmental conditions, certain plant secretions, and bacterial regulators. In our previous work, a member of the LysR family of transcriptional regulators (LsrB) in Sinorhizobium meliloti was found to modulate its symbiotic interactions with the host plant alfalfa. However, the function of its homolog in A. tumefaciens remains unclear. In this study, we show that the LsrB protein of $A$. tumefaciens is required for efficient transformation of host plants. A $l s r B$ deletion mutant of $A$. tumefaciens exhibits a number of defects, including in succinoglycan production, attachment, and resistance to oxidative stress and iron limitation. RNA-sequencing analysis indicated that $\mathbf{4 6 5}$ genes were significantly differentially expressed (upregulation of 162 genes and downregulation of 303 genes) in the mutant, compared with the wild-type strain, including those involved in succinoglycan production, iron transporter, and detoxification enzymes for oxidative stress. Moreover, expression of the $l s r B$ gene from $S$. meliloti, Brucella abortus, or $A$. tumefaciens rescued the defects observed in the $S$. meliloti or A. tumefaciens $l s r B$ deletion mutant. Our findings suggest that a conserved mechanism of LsrB function exists in symbiotic and pathogenic bacteria of the family Rhizobiaceae.
\end{abstract}

Agrobacterium tumefaciens is a facultative plant pathogen that induces crown gall diseases in dicot plants. During infection, a DNA fragment (T-DNA) from the A. tumefaciens Ti plasmid is transferred to plant cells and integrates into the plant genome; the transgene-encoded proteins drive the synthesis of phytohormones, cytokinins, and auxin, which elicit plant cell proliferation and tumorigenesis (Thomashow et al. 1984; White and Braun 1941). This process requires the VirB/D4 type IV secretion system (T4SS) of A. tumefaciens. Because of its ability

${ }^{\dagger}$ Corresponding author: Li Luo; E-mail: liluo@shu.edu.cn

Funding: This research was supported by the Natural Science Foundation of China (31570241 to L. Luo, 31500058 to G. Tang and 31500197 to L. $\mathrm{Yu}$ ) and the Science and Technology Commission of Shanghai Municipality (15230500100 to L. Luo).

*The $\boldsymbol{e}$-Xtra logo stands for "electronic extra" and indicates that four supplementary figures and three supplementary tables are published online.

@ 2018 The American Phytopathological Society to transfer DNA to plants, A. tumefaciens has been developed as an important tool in plant genetic transformation and engineering (Azpiroz-Leehan and Feldmann 1997).

The virulence (vir) gene located on the Ti plasmid is essential for T-DNA transfer and tumorigenesis. A. tumefaciens possesses a VirA/VirG two-component regulatory system that senses important environmental signals, including acidity, monosaccharides, and phenolic compounds such as acetosyringone, which are released by wounded plant cells, to regulate vir gene induction (Bhattacharya et al. 2010; Brencic and Winans 2005; Lacroix and Citovsky 2013; Palmer et al. 2004; Pitzschke and Hirt 2010; Shimoda et al. 1990). Plants generate high levels of reactive oxygen species (ROS), such as $\mathrm{H}_{2} \mathrm{O}_{2}$ and superoxide radicals, which are employed in an important initial defense mechanism to inhibit bacterial invasion and proliferation (Baker and Orlandi 1995). Catalase and superoxide dismutase are crucial antioxidant enzymes that degrade $\mathrm{H}_{2} \mathrm{O}_{2}$ and superoxides, respectively. These enzymes have been shown to serve as virulence factors involved in A. tumefaciens tumorigenesis (Saenkham et al. 2007; Xu and Pan 2000). Iron ions are also key players in maintaining redox homeostasis in bacteria. Homologous iron-sensing regulatory ferric uptake regulation (fur) genes from plant pathogens have been shown to play a critical role during plant-pathogen interaction (Franza et al. 1999; Subramoni and Sonti 2005). In addition, plant mechanisms for depriving invading microbes of iron have been suggested (Neema et al. 1993). Therefore, plant pathogens need to overcome both oxidative stress and iron deprivation for survival and proliferation in host plants. The A. tumefaciens catalase KatA is an important virulence factor involved in the detoxification of $\mathrm{H}_{2} \mathrm{O}_{2}$ released from plant tumors (Xu and Pan 2000; Xu et al. 2008). Expression of katA in A. tumefaciens is regulated by OxyR, a LysR family transcriptional regulator that is responsible for bacterial resistance to oxidative stress (Nakjarung et al. 2003). A. tumefaciens, B. abortus, and $S$. meliloti are members of family Rhizobiaceae and these are conserved in a much larger family, such as OxyR/KatA homologs (Jamet et al. 2005).

In our previous work, a new LysR family transcriptional regulator gene, $l s r B$, required for nodulation and nitrogen fixation (Luo et al. 2005), was identified in Sinorhizobium meliloti. A $l s r B$ deletion mutant induced the formation of inefficient nitrogenfixing root nodules on host alfalfa plants (Medicago sativa) (Tang et al. 2013). As LsrB directly regulates the expression of genes involved in lipopolysaccharide biosynthesis and glutathione production (Lu et al. 2013; Tang et al. 2014), it constitutes a new redox regulator in $S$. meliloti (Tang et al. 2017). A homolog of $l s r B$ has also been identified in Brucella species (Foulongne et al. 
2000; Sheehan et al. 2015). However, the function of LsrB in A. tumefaciens has not yet been determined.

In this work, we constructed an A. tumefaciens $l s r B$ deletion mutant and examined it for both free-living and pathogenic phenotypes. We identified new functions of LsrB in A. tumefaciens and, also, compared the functions and mechanisms of three LsrB proteins from B. abortus, S. meliloti, and A. tumefaciens. A conserved mechanism of LsrB in all three species is proposed.

\section{RESULTS}

Expression of the pathogenic bacterial $l s r B$ gene rescued the symbiotic defects of the $S$. meliloti $l s r B$ mutant.

Homologous $l s r B$ genes have been identified in several bacterial species, including members of Sinorhizobium and Brucella (Tang et al. 2013; Sheehan et al. 2015). The LsrB proteins from A. tumefaciens and B. abortus share 88 and $69 \%$ identity with the $S$. meliloti LsrB protein, respectively. These proteins are composed of a DNA-binding domain and a LysR substrate-binding domain (Fig. 1A; Supplementary Fig. S1), and the observed protein sequence identity suggests that they may share the same function or mechanism of action.

To assess this possibility, the $S$. meliloti $l s r B$ deletion $(\Delta l s r B)$ mutant, which induces defective nitrogen-fixation nodules on alfalfa, was used in a symbiotic nodulation assay with alfalfa plants (Tang et al. 2013). In Rhizobium-legume symbiosis, mutants that induce less effective nitrogen -fixation nodules can induce the production of a larger number of the plant organs (Oka-Kira and Kawaguchi 2006). The $l s r B$ gene from A. tumefaciens or B. abortus was expressed in the $S$. meliloti $\Delta l s r B$ mutant, and each strain was inoculated onto alfalfa seedlings. After four weeks, the growth of plants inoculated with the $l s r B$ deletion mutant expressing the $l s r B$ gene from either A. tumefaciens or B. abortus was similar to that of plants inoculated with the wild-type strain of $S$. meliloti (Rm1021) (Fig. 1B). Additionally, the biomass (dry weight) and number of

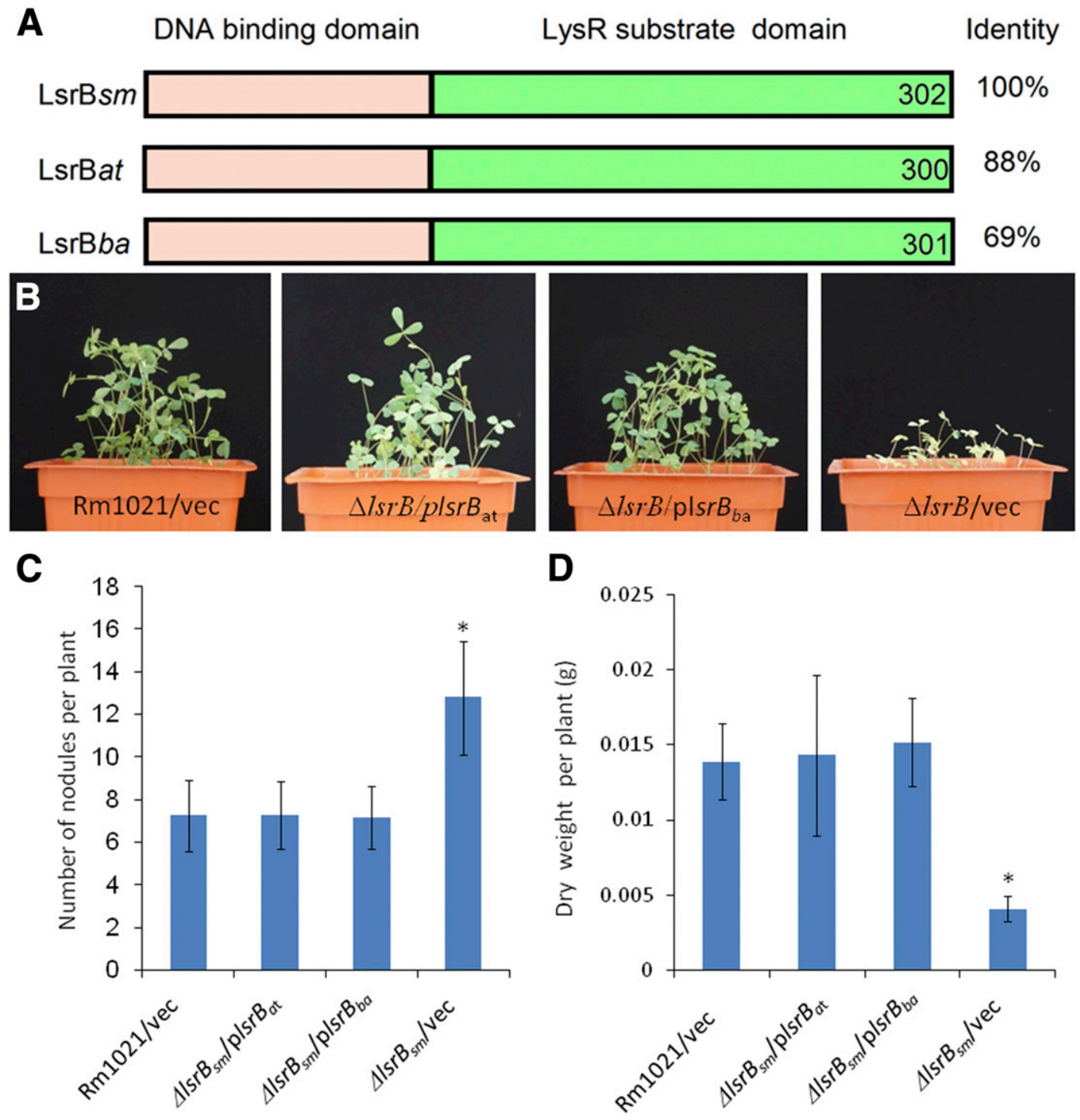

Fig. 1. Conservation among LsrB proteins from Sinorhizobium meliloti, Agrobacterium tumefaciens, and Brucella abortus. A, Domain organization of LsrB proteins from S. meliloti, A. tumefaciens, and B. abortus. LsrB proteins consist of DNA-binding and substrate-binding domains. LsrB homologs from A. tumefaciens and B. abortus share 88 and $69 \%$, respectively, similarity in amino-acid sequence with the protein from S. meliloti. B, Alfalfa plant growth after inoculation of the $S$. meliloti $\Delta l s r B$ strain expressing an A. tumefaciens or B. abortus lsrB homolog. C, Nodule numbers of alfalfa plants inoculated with S. meliloti strains. D, Biomass of alfalfa plants inoculated with S. meliloti strains. Experiments were performed three times. A total of 45 alfalfa seedlings were inoculated with each $S$. meliloti strain. Vertical bars indicate the standard error for three independent experiments. An asterisk $(*)$ denotes a significant difference from Rm1021/vec in a $t$ test $(<0.05)$. $\Delta l s r B$, the deletion mutant of $l s r B$ in the $S$. meliloti 1021 background; $\mathrm{pls} r B_{\text {at }}$, the $l s r B$ gene of $A$. tumefaciens C58C1 expressed from the plasmid pSRK-Gm; $l_{s r} B_{b a}$, the $l s r B$ gene of $B$. abortus expressed from the plasmid pSRK-Gm; vec, the plasmid pSRK-Gm. 
nodules of plants induced by the mutant expressing $l s r B_{a t}$ or $l s r B_{b a}$ were found to be similar to those induced by $\mathrm{Rm} 1021$ (Fig. 1C and D). These results indicate that the $l s r B$ gene from A. tumefaciens or B. abortus completely rescued the symbiotic defects of the $S$. meliloti lsrB deletion mutant, suggesting that these LsrB proteins have conserved physiological functions or molecular mechanisms in both symbiotic and pathogenic bacteria.

\section{The A. tumefaciens $\Delta l s r B$ mutant is deficient} in host plant transformation.

To determine new functions of the $l s r B$ gene during interactions with hosts, an $A$. tumefaciens $l s r B$ deletion mutant was constructed using a suicide-plasmid homologous recombination method (discussed below). For the complementation analysis, a plasmid expressing the $l s r B$ gene from A. tumefaciens, $B$. abortus, or $S$. meliloti was introduced into the $\Delta l s r B$ mutant. In addition, a plant-expression vector pCAMBIA2301 (Cambia, Canberra, Australia) carrying a $C A M V-35 S$ driven-GUS gene was transferred into each $A$. tumefaciens strain for the plant transformation assay. Roots of young Arabidopsis seedlings were treated with each strain, and $\beta$-glucuronidase (GUS) activity in wounds was determined. The results showed that the $l s r B$ deletion mutant induced fewer (less than one-tenth as many) transformation events than the parent strain $\mathrm{C} 58 \mathrm{C} 1$, whereas the plasmid expressing the $l s r B$ gene from A. tumefaciens, $B$. abortus, or $S$. meliloti completely rescued the defect of the mutant (Fig. 2). These results suggest that LsrB is required for A. tumefaciens transformation of host plants.
The $l s r B$ gene is required for efficient attachment of $A$. tumefaciens onto host plants.

As bacterial attachment is a key step in the infection of a host plant by A. tumefaciens (Lippincott and Lippincott 1969), we evaluated the attachment efficiency of the A. tumefaciens lsrB deletion mutant onto Arabidopsis roots. Roots were soaked in fresh cell suspensions of $A$. tumefaciens constitutively expressing green fluorescent protein (GFP), and attached cells were analyzed under a fluorescence microscope after $2 \mathrm{~h}$. Compared with Arabidopsis roots inoculated with the parent strain C58C1, weaker fluorescence intensity was observed in the Arabidopsis roots inoculated with the $l s r B$ deletion mutant (Fig. 3A and B). This defect was rescued by expressing the $l s r B$ gene from A. tumefaciens, B. abortus, or S. meliloti (Fig. 3C to E). The numbers of bacterial cells attached to the plant roots were counted by diluting and plating samples. Significantly fewer cells of the $l s r B$ deletion strain were present compared with the parent strain $\mathrm{C} 58 \mathrm{C} 1$, and higher counts were observed after introducing the $l s r B$ gene from any of the three bacterial species (Fig. 3F). These results suggest that LsrB is a positive regulator of Agrobacterium attachment onto host plants.

\section{The LsrB protein positively regulates succinoglycan and biofilm production in $A$. tumefaciens.}

The A. tumefaciens $l s r B$ deletion mutant grew slightly slower in liquid medium, compared with the parent strain $\mathrm{C} 58 \mathrm{C} 1$, and this defect was rescued by the expression of the $l s r B$ gene from
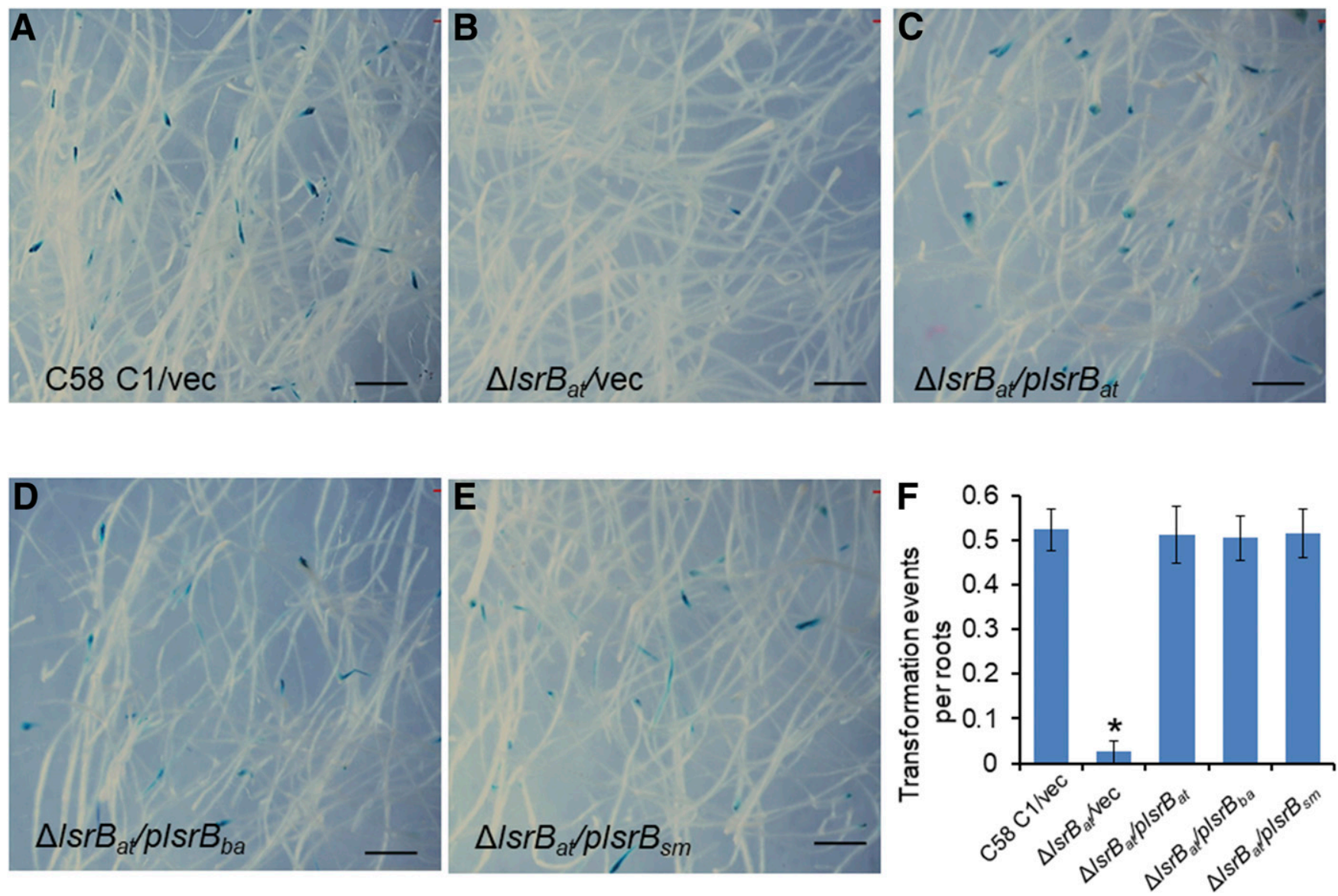

Fig. 2. Transformation of Arabidopsis with wounded roots by Agrobacterium tumefaciens strains. A to E, Arabidopsis root segments transformed by different A. tumefaciens strains carrying pCAMBIA2301. F, Mean numbers of blue spots in Arabidopsis root segments induced by each different $A$. tumefaciens strain. Experiments were performed three times. Over 50 Arabidopsis seedlings were inoculated with each A. tumefaciens strain carrying pCAMBIA2301. Vertical bars indicate the standard error for three independent experiments. An asterisk $\left(^{*}\right)$ denotes a significant difference from C58C1/vec in a $t$ test $(<0.05)$. Bars $=$ $1 \mathrm{~mm}$. 
A. tumefaciens, B. abortus, or S. meliloti (Supplementary Fig. $\mathrm{S} 2$ ). Interestingly, the colonies of the $l s r B$ deletion mutant did not appear mucoid, which prompted us to evaluate exopolysaccharide (EPS) (succinoglycan) production by the mutant. The fluorescent stain Calcofluor white M2R, which can specifically bind to succinoglycan, was used to evaluate succinoglycan production by $A$. tumefaciens, showing that the colonies of the $l s r B$ deletion mutant produced weaker fluorescence than did the wild-type strain (Fig. 4A). The introduction of plasmids expressing the $l s r B$ genes from $A$. tumefaciens, $B$. abortus, or $S$. meliloti restored succinoglycan production in the $l s r B$ deletion mutant (Fig. 4A). Quantitative analysis of the fluorescence intensity revealed that fivefold more succinoglycan was produced by the parent and complemented strain compared with the $l s r B$ deletion mutant (Fig. 4B). The total sugar content in the exopolysaccharide produced by $A$. tumefaciens growing in broth was analyzed using an anthrone sulphuric acid method, and the results revealed significantly decreased total sugar for the $l s r B$ mutant compared with the parent or complemented strain (Fig. 4C). Additionally, biofilm formation by each $A$. tumefaciens strain in tubes was examined. Based on visual inspection, the $l s r B$ mutant formed only a small amount of biofilm, whereas the parent and complemented strains produced a large amount of biofilm. Furthermore, quantification of the biofilm using crystal violet showed less biofilm on tubes formed by the $l s r B$ deletion mutant compared with the parent or complemented strain (Fig. 4D). These results indicate that the LsrB protein positively regulates succinoglycan production and biofilm formation in A. tumefaciens.

\section{The LsrB protein is essential for A. tumefaciens adaptation} to oxidative stress and iron limitation.

The increased expression of KatA exhibited by the $S$. meliloti $l s r B$ deletion mutant (Tang et al. 2013) suggests that this mutant is sensitive to oxidative stress. Similarly, in the present study, we hypothesized that the $A$. tumefaciens $l s r B$ deletion mutant may also be sensitive to these oxidizing agents. To test this possibility, cell sensitivity assays using hydrogen peroxide $\left(\mathrm{H}_{2} \mathrm{O}_{2}\right)$ and sodium nitroprusside (SNP) were performed. A. tumefaciens $\Delta l s r B$ cells were found to be hypersensitive to $10 \mathrm{mM} \mathrm{H}_{2} \mathrm{O}_{2}$ and $10 \mathrm{mM}$ SNP (Fig. 5), and this defect was rescued by expressing of the $l s r B$ gene from A. tumefaciens, B. abortus, or S. meliloti (Fig. 5). These results suggest that the ability of $A$. tumefaciens to resist oxidative stress is positively influenced by the LsrB protein.

Bacterial adaptation to oxidative stress is associated with intracellular redox homeostasis, which is influenced by levels of iron ions. To determine whether A. tumefaciens $l s r B$ contributes to iron transport, sensitivity to Dipy (2, 2-dipyridyl, a metal ion chelator) was analyzed. Our data indicated that the $l s r B$ deletion mutant was hypersensitive to Dipy both on solid and liquid media, and this defect was rescued by expressing the $l s r B$ gene from $A$. tumefaciens, $S$. meliloti, or B. abortus (Fig. 6). Moreover, addition of $\mathrm{FeCl}_{3}$ was able to restore the resistance of the mutant to Dipy (Fig. 6). These data
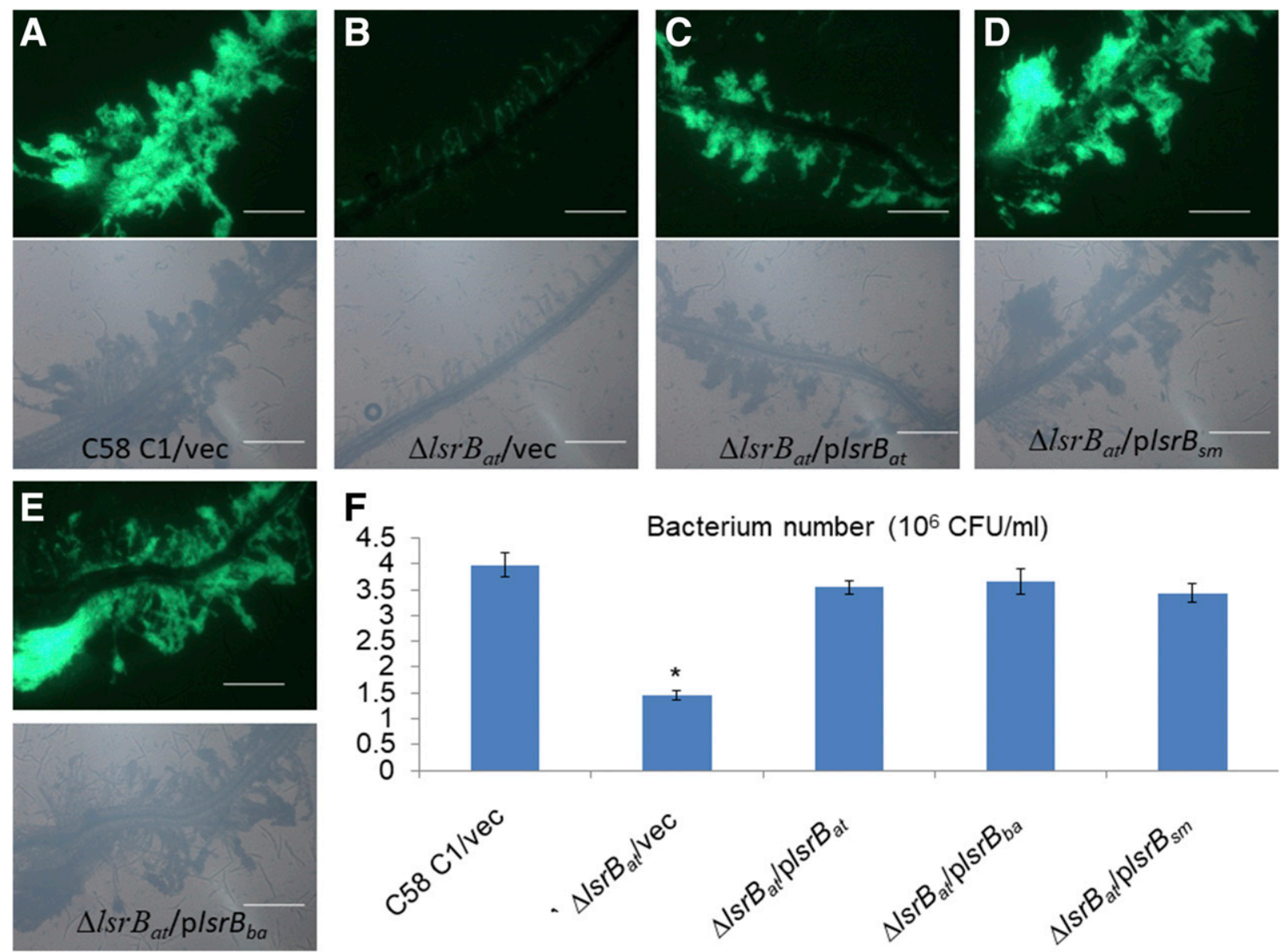

Fig. 3. Attachment to Arabidopsis roots by Agrobacterium tumefaciens strains. A to E, Attachment of A. tumefaciens cells to Arabidopsis roots. F, Number of bacteria attached to Arabidopsis roots. Experiments were performed three times. Over 20 Arabidopsis seedlings were inoculated with each A. tumefaciens strain carrying pHC60 (a constitutive green fluorescent protein gene construct). Vertical bars indicate the standard error for three independent experiments. An asterisk $(*)$ denotes a significant difference from C58C1/vec in a $t$ test $(<0.05)$. Bars $=1 \mathrm{~mm}$. 
indicate that LsrB is a positive regulator of iron homeostasis in A. tumefaciens.

\section{The $l s r B$ deletion mutant exhibits decreased survival} in infiltrated tobacco leaves.

To confirm that LsrB is required for A. tumefaciens transformation of host plants, young tobacco leaves were used for infiltration experiments with suspensions of bacteria harboring the $G U S$ reporter gene. Staining results indicated a lower level of $G U S$ expression in leaves infiltrated with the $l s r B$ deletion strain than in leaves infiltrated with the parent strain $\mathrm{C} 58 \mathrm{C} 1$ at the same bacterial density (Fig. 7A). It is well-known that plant wounds release several chemicals, including ROS (superoxide anions and hydrogen peroxide) (Baker and Orlandi 1995). To determine factors affecting transformation efficiency, nitroblue tetrazolium (NBT) staining was used to assess superoxide anion radical accumulation. The data confirmed that infiltrated tobacco leaves produced large amounts of $\mathrm{O}_{2}^{-}$(Fig. $7 \mathrm{~B}$ and $\mathrm{C}$ ). In addition, the bacteria infiltrated into tobacco leaves were recovered, were plated, and were counted. Starting 1 day after inoculation, we detected a lower recovered bacterial cell density of the $l s r B$ deletion mutant than with the parent strain (Fig. 7D; Supplementary Fig. S3), suggesting that the proliferation or survival of A. tumefaciens cells in the wounds of host plants
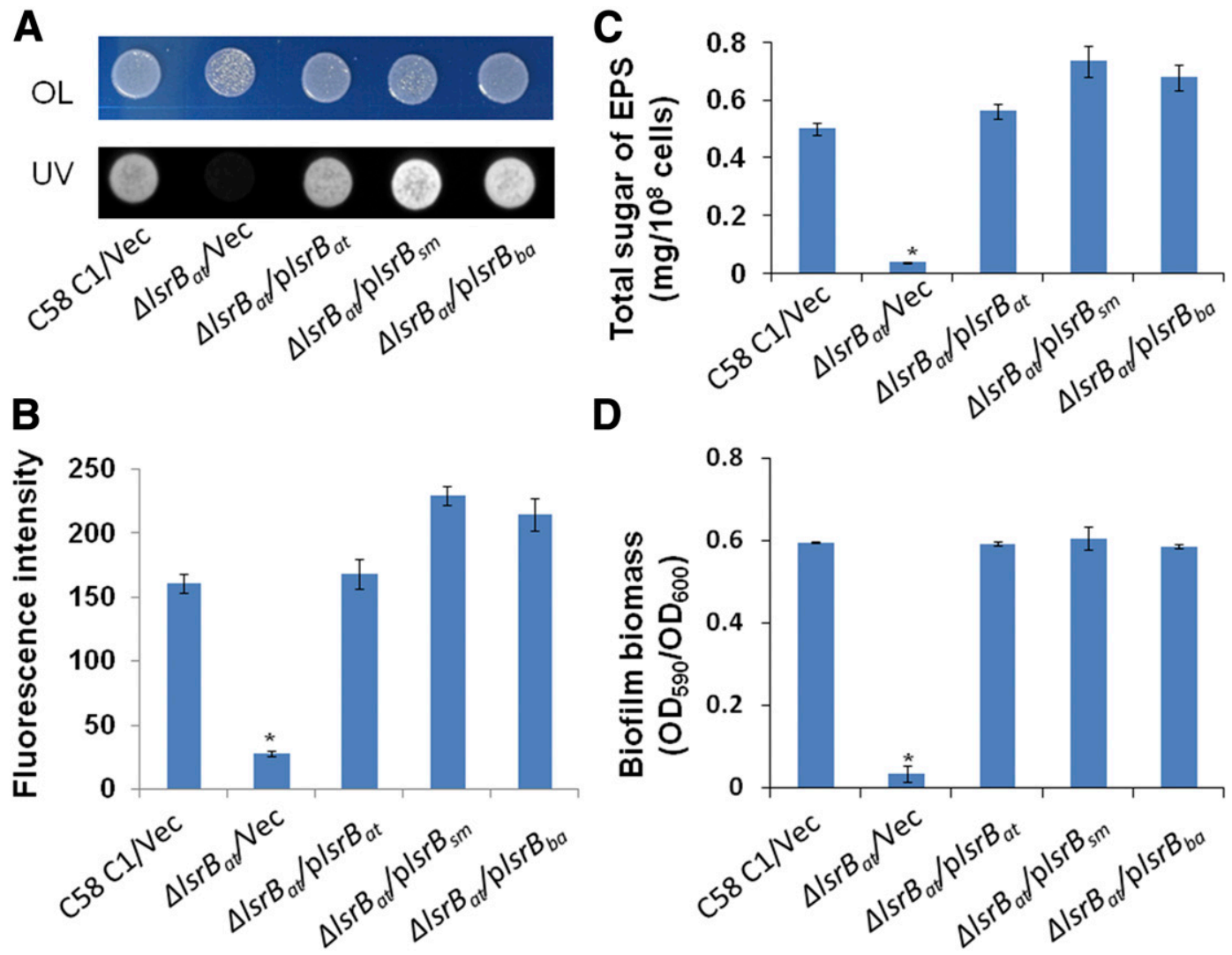

Fig. 4. Exopolysaccharide (EPS) production and biofilm formation by Agrobacterium tumefaciens strains. A, EPS stained by Calcofluor white and bacterial colonies under optical light (OL) and UV light (UV) are shown. B, Fluorescence intensity of EPS was analyzed using ImageJ software. C, Quantification of the total EPS produced by A. tumefaciens strains in Luria Bertani broth. The sulfate-anthrone method was used and this experiment was performed three times. Vertical bars indicate the standard error for three independent experiments. An asterisk $\left(^{*}\right)$ denotes a significant difference from C58C1/vec in a $t$ test $(<0.05)$. D, Biofilm produced by bacterial strains using a crystal violet staining method. Vertical bars indicate the standard error for three independent experiments. An asterisk $(*)$ denotes a significant difference from $\mathrm{C} 58 \mathrm{C} 1 / \mathrm{vec}$ in a $t$ test $(<0.05)$.

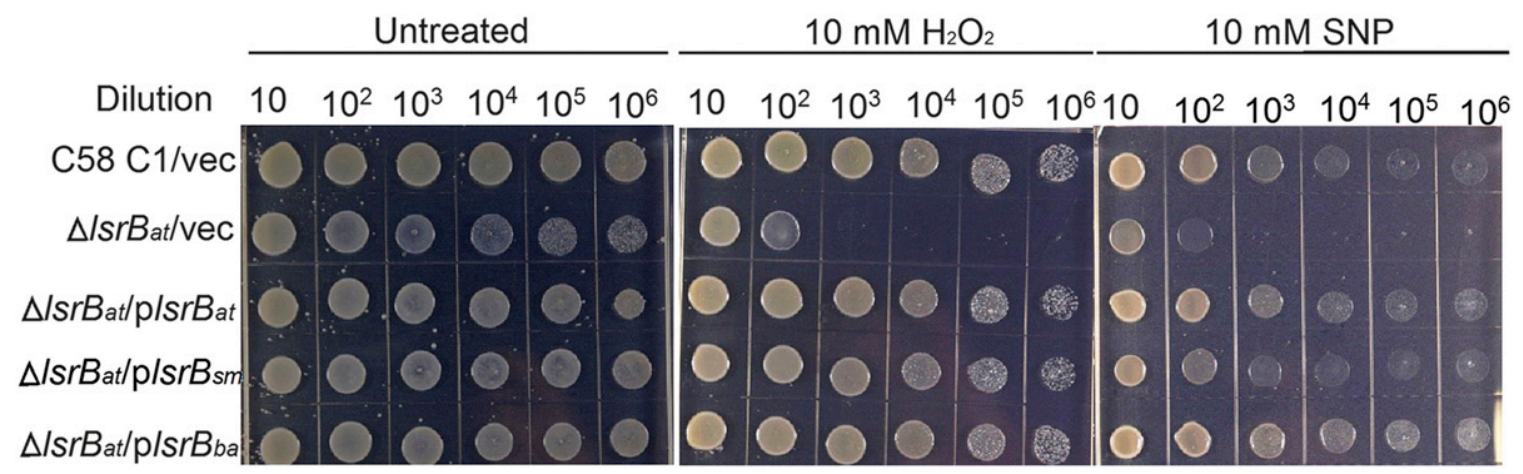

Fig. 5. Sensitivity of Agrobacterium tumefaciens strains to oxidants. A. tumefaciens strains were cultured to an optical density at $600 \mathrm{~nm}=0.5$, were diluted, and were spot-inoculated onto Luria Bertani medium containing either $10 \mathrm{mM} \mathrm{H}_{2} \mathrm{O}_{2}$ or $10 \mathrm{mM}$ sodium nitroprusside (SNP). The experiment was performed three times. 
requires the LsrB protein and may be associated with ROS sensitivity.

\section{Downstream gene expression}

in the A. tumefaciens $l s r B$ deletion mutant.

Due to the multiple phenotypic defects induced by $l s r B$ deletion in A. tumefaciens, it seemed plausible that multiple genes are differentially expressed in the mutant compared with the parent strain. To assess this possibility, the wholegenome transcriptomes of both the deletion mutant and the parent strain were analyzed by RNA sequencing (RNA-Seq) (Supplementary Table S3), and genes identified as being differentially expressed were selected for confirmation by quantitative reverse transcription-polymerase chain reaction (RT-qPCR). The transcript levels of 14 of the selected genes; attD, exoV, exoC, exoP, oxyR, trxA, Atu3676, Atu3679, Atu3680, Atu3688 ( $\mathrm{fecB}$ ), Atu3690 (fecD), and Atu3691 $(f e c E)$ were decreased in the $l s r B$ deletion mutant and oxidative stress (katA) and succinoglycan production (exoR) were increased in the $l s r B$ deletion mutant (Fig. 8). These data indicate that the expression of several genes associated with adaptation to oxidative stress $($ oxyR, $\operatorname{tr} x A)$, succinoglycan production (exoV, exoC, exoP), siderophore biosynthesis $(f e c B, f e c D, f e c E)$, and iron transporter (Atu3676, Atu3679, Atu3680) is positively regulated by the LsrB protein.

\section{DISCUSSION}

A. tumefaciens causes crown gall on plants and is used in plant genetic engineering. Transformation of plant cells via A. tumefaciens depends on bacterial adaptation to the environment of plant wounds. Indeed, bacteria have developed several strategies to perceive environmental signals from plant wounds to reprogram their gene expression. Members of the LysR-type family of regulators are able to sense environmental cues and function as key players in these processes (Maddocks and Oyston 2008; Schell 1993). The $l s r B$ gene, which was first identified in Brucella suis (Foulongne et al. 2000) and later in S. meliloti (Luo et al. 2005), is essential for alfalfa nodulation and nitrogen fixation by S. meliloti (Tang et al. 2013) and for Brucella infection and survival in a human cell line and mice (Sheehan et al. 2015; Tang et al. 2013). In this study, we found that LsrB, an A. tumefaciens LysR family regulator, overcomes both oxidative stress and iron deprivation and controls transformation efficiency in host plants. These findings are important for understanding the regulatory mechanism of the interaction of $A$. tumefaciens with its hosts.

For many years, att genes were proposed to mediate attachment and were also reported to be required for virulence (Matthysse et al. 2000). However, the genome sequence of A. tumefaciens C58 (Goodner et al. 2001; Wood et al. 2001) revealed the att cluster to be located on the plasmid pAtC58, which is known to be dispensable for virulence (Hynes et al.
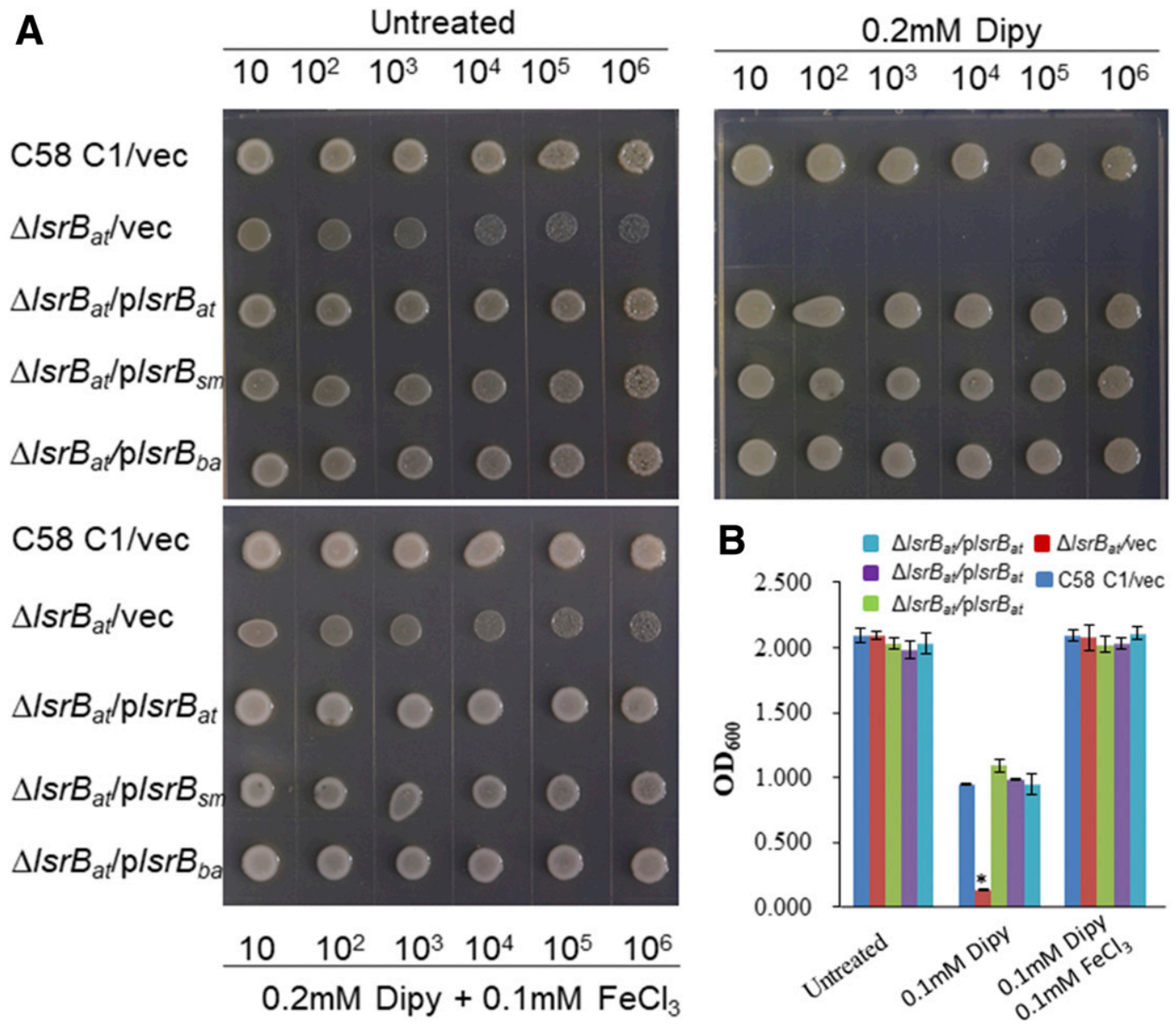

Fig. 6. Sensitivity of the Agrobacterium tumefaciens strain to Dipy. A, Effect of the addition of metal ions to growth in the presence of Dipy. Cells were diluted and spotted onto tryptone yeast (TY) agar plates containing $0.2 \mathrm{mM}$ Dipy and $0.1 \mathrm{mM} \mathrm{FeCl}_{3}$ and were then incubated at $28^{\circ} \mathrm{C}$ for 4 days. Cells spotted onto a TY agar plate were used as a control. B, Cells were grown in TY medium, TY medium containing 0.1 mM Dipy, and TY medium containing 0.1 mM Dipy and $0.1 \mathrm{mM} \mathrm{FeCl}_{3}$. Growth was monitored by measuring the density at $600 \mathrm{~nm}$ after incubation at $28^{\circ} \mathrm{C}$, with shaking, for $36 \mathrm{~h}$. Vertical bars indicate the standard error for three independent experiments. An asterisk $(*)$ denotes a significant difference from C58C1/vec in a $t$ test $(<0.05)$. 
1985). Analysis using isogenic derivatives revealed that pAtC58 has only mild effects on virulence gene expression, with no obvious impact on attachment (Nair et al. 2003). Although our data do not address whether the att genes are directly associated with attachment, we note that it did find significantly lower expression of attD as well as diminished attachment with the $l s r B$ mutant (Figs. 3 and 8). Additionally, the $a v h B$ genes, encoding the T4SS that mediates conjugation of pAtC58, was also decreased in the $l s r B$ mutant, which could possibly be relevant to the diminished attachment.

Based on the results of our study, LsrB is a positive regulator of exopolysacchride (including succinoglycan) production (Fig. 4), and we confirmed that LsrB positively regulates succinoglycan biosynthesis by activating exo gene expression (Fig. 8). For example, expression of exoR was upregulated in the $l s r B$ deletion mutant. ExoR acts as a negative regulator of succinoglycan biosynthesis by suppressing the ChvG/ChvI twocomponent system, which directly activates expression of exo genes in both S. meliloti and A. tumefaciens (Chen et al. 2008; Wells et al. 2007; Wu et al. 2012). Therefore, our data suggest that increased levels of ExoR led to the repression of the exo genes via ChvG/ChvI.

The plant transformation deficiency of the $l s r B$ deletion mutant might largely result from the decrease in bacterial adaptation to the environment. In this study, we found the freeliving $l s r B$ mutant to be sensitive to oxidants (Fig. 5), which is consistent with the observations in plants (Fig. 7). Upon wounding, an oxidative burst is induced in plants (Fig. 7B and $\mathrm{C})$, and the sensitivity of the mutant to this condition may lead to bacterial cell death (Fig. 7D). We also observed the mutant to be hypersensitive to iron limitation (Fig. 6). Iron transport plays a crucial role in redox homeostasis (Imlay et al. 1988) and iron limitation has been suggested to occur during bacterium-plant interactions (Mila et al. 1996; Neema et al. 1993); thus, ironlimitation sensitivity may also contribute to bacteria survival in wounds. Consistently, the expression of genes related to the oxidative response and detoxification and iron transporters was correspondingly altered in the mutant (Fig. 8).

The regulatory mechanism of LsrB in bacteria may be conserved. First, the $l s r B$ gene from B. abortus, A. tumefaciens, or $S$. meliloti can complement the $l s r B$ deletion mutant phenotype in A. tumefaciens and S. meliloti (Figs. 1 to 6). Second, the LsrB protein could directly regulate expression of lrp3 (though function of this gene is not clear) in both S. meliloti and A. tumefaciens, as conserved TN11A boxes are predicted to be present in the lrp3 promoter (Supplementary Fig. S4) and the LsrB proteins directly bind to the $\operatorname{lrp} 3$ promoter region in S. meliloti (Tang et al. 2014). In summary, our results reveal that LsrB is a global regulator in the interaction of A. tumefaciens with host plants, a finding that is important for understanding the molecular mechanism and evolution of bacterial adaptation to biotic environments.

\section{MATERIALS AND METHODS}

Bacterial strains, plasmids, and growth conditions.

All bacterial strains and plasmids used in this study are listed in Supplementary Table S1. The reagents and medium components were obtained from Dingguo Corporation (Beijing) and Sigma-Aldrich (Shanghai, China). All restriction enzymes
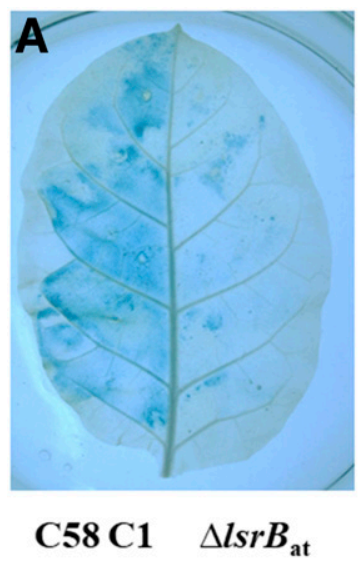

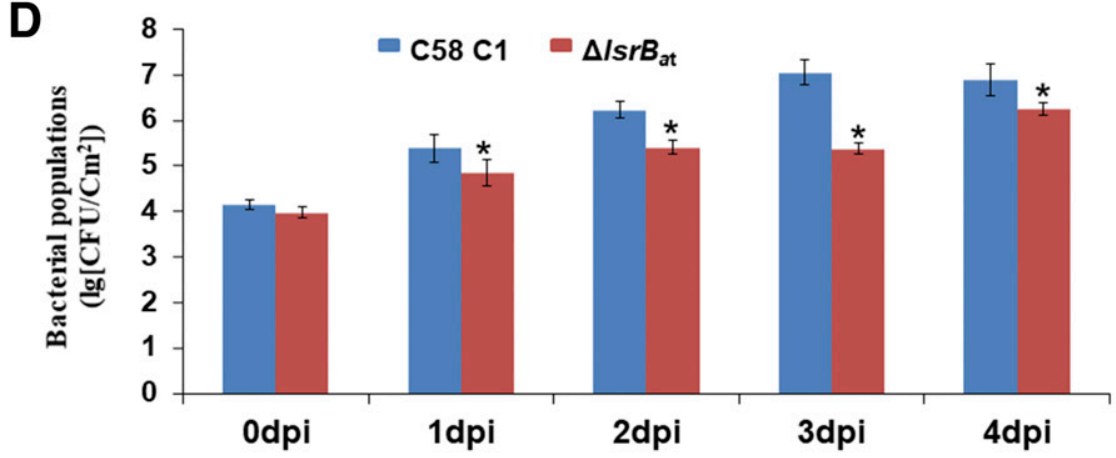

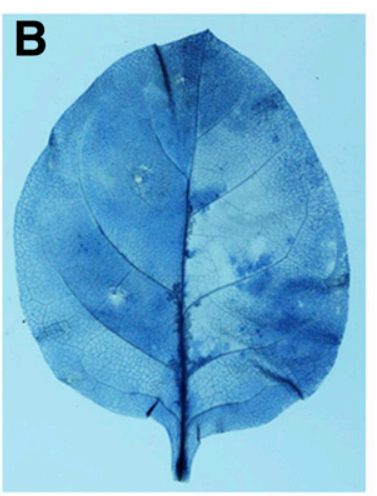

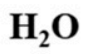

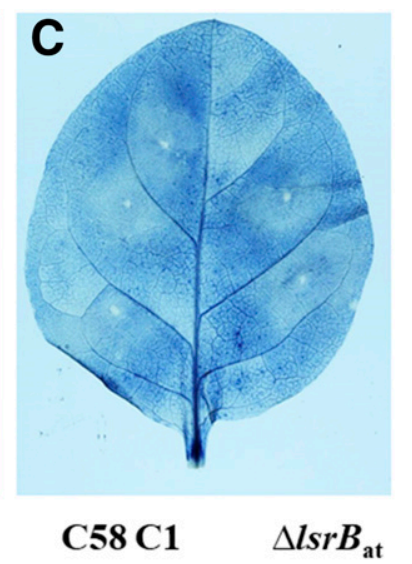

$\mathrm{C58C1} \quad \Delta l s r B_{\text {at }}$

Fig. 7. Transient transformation of tobacco leaves mediated by Agrobacterium tumefaciens strains. A, Transient transformation of tobacco leaf cells by A. tumefaciens. Over 20 tobacco leaves were infiltrated with $A$. tumefaciens carrying pCAMBIA2301 construct. Bars $=1$ mm. B, and $\mathbf{C}$, Superoxide anion radical accumulation in tobacco leaves stained with nitroblue tetrazolium after infiltration of $\mathrm{H}_{2} \mathrm{O}$ and suspensions of $A$. tumefaciens cells, respectively. The - denotes an untreated leaf. These experiments were performed three times. Over 20 tobacco leaves were infiltrated with A. tumefaciens strains. Bars = 1 mm. D, Bacterial populations from infiltrated tobacco leaves. Vertical bars indicate the standard error for three independent experiments. An asterisk (*) denotes a significant difference from C58C1/vec in a $t$ test $(<0.05)$. 
and molecular biology reagents were purchased from TakaRa (Dalian, China). DNA sequences were determined by Shanghai RuiDi Biological Technology Corporation. The oligonucleotide primers used in this study are listed in Supplementary Table S2. Escherichia coli was grown aerobically at $37^{\circ} \mathrm{C}$ in LuriaBertani (LB) medium (Sambrook et al. 1989). A. tumefaciens were grown aerobically at $28^{\circ} \mathrm{C}$ in tryptone yeast (TY) medium (Beringer 1974) or LB medium. Antibiotics were used at the following concentrations: chloramphenicol, $10 \mu \mathrm{g} \mathrm{ml}^{-1}$; kanamycin, $50 \mu \mathrm{g} \mathrm{ml}^{-1}$; gentamicin, $10 \mu \mathrm{g} \mathrm{ml}{ }^{-1}$; streptomycin, $500 \mu \mathrm{g} \mathrm{ml}^{-1}$; rifampicin, $50 \mu \mathrm{g} \mathrm{ml}^{-1}$; and timentin, $200 \mu \mathrm{g} \mathrm{ml}^{-1}$.

\section{Construction of deletion strains.}

Fragments upstream and downstream of $l s r B_{a t}$ were amplified using primers P1 and P2 (upstream) and P3 and P4 (downstream). Primer P2 was designed such that the $5^{\prime}$ sequence had reverse complementarity to primer P3. The complementary sequence of these two primers facilitated splicing by overlapping the extension of the two PCR products. Both flanking sequences were amplified and gel-purified. The two purified products were then used as both templates and primers (P1 and P4) in a second PCR reaction to generate the final spliced product, which was ligated to pmD18 (TakaRa) and was sequenced. The deletion construct was then excised using restriction enzymes and was ligated to the suicide vector pk18mobsacB (Schäfer et al. 1994), to produce plasmid pA1. The pk18mobsacB plasmid confers kanamycin resistance and sucrose sensitivity. Plasmid pA1 was introduced into A. tumefaciens C58C1 (Jelenic et al. 2000) via mating, using MT616 (Finan et al. 1984), and A. tumefaciens C58C1 was obtained from Shanghai Weidi Biotechnology Co., Ltd. Exconjugants with kanamycin resistance were screened on LB plates and were selectively grown on fresh LB plates containing $13 \%$ sucrose. The resulting colonies were tested for neomycin sensitivity. Corrected $l s r B_{a t}$ mutants were confirmed by PCR using primers (P5 or P6) flanking the deletion site.

\section{Plasmid expression constructs.}

To construct a plasmid for complementation of the $\Delta l s r B_{a t}$ mutant, a $l \mathrm{~s} r B$ DNA fragment that included the native promoter was PCR-amplified from the genomic DNA of A. tumefaciens C58C1, using primers $\mathrm{P} 9$ and $\mathrm{P} 10$. The PCR product was cloned into pSRK (Khan et al. 2008) and the plasmid was named $\mathrm{p} l s r B_{a t}$. The $B$. abortus 2308 lsrB homolog, including its native promoter, was amplified using primers P7 and P8 and was cloned into pSRK; the plasmid was named $\mathrm{p} l s r B_{b a}$. The $S$. meliloti 1021 lsrB homolog, including its native promoter, was amplified using primers P11 and P12 and was cloned into pSRK; the plasmid was named $\mathrm{p} l s r B_{s m}$. The constructs were introduced into the $\Delta l s r B_{a t}$ strain via conjugation.

\section{RNA extraction.}

Subcultures were started by inoculation of $50 \mathrm{ml}$ of fresh TY medium with $5 \%$ of the overnight cultures and were allowed to grow to log phase (density at $600 \mathrm{~nm}\left[\mathrm{OD}_{600}\right]=0.5$ ), RNA was isolated using TRIZOL reagent (Invitrogen, Carlsbad, CA, U.S.A.) and cDNA was prepared using a kit (TakaRa). An Agilent 2100 Bioanalyzer (Santa Clara, CA, U.S.A.) was used to assess the integrity of the RNA samples. RNA-Seq was carried out by Shanghai Bohao Biological Technology Corporation. The accession number for the RNA-seq data is GEO: GSE108845. qPCR primers were designed to amplify approximately 200-bp sequences from the indicated genes. The qPCR procedure was performed with SYBR Green reagent (Yeasen, Shanghai, China).

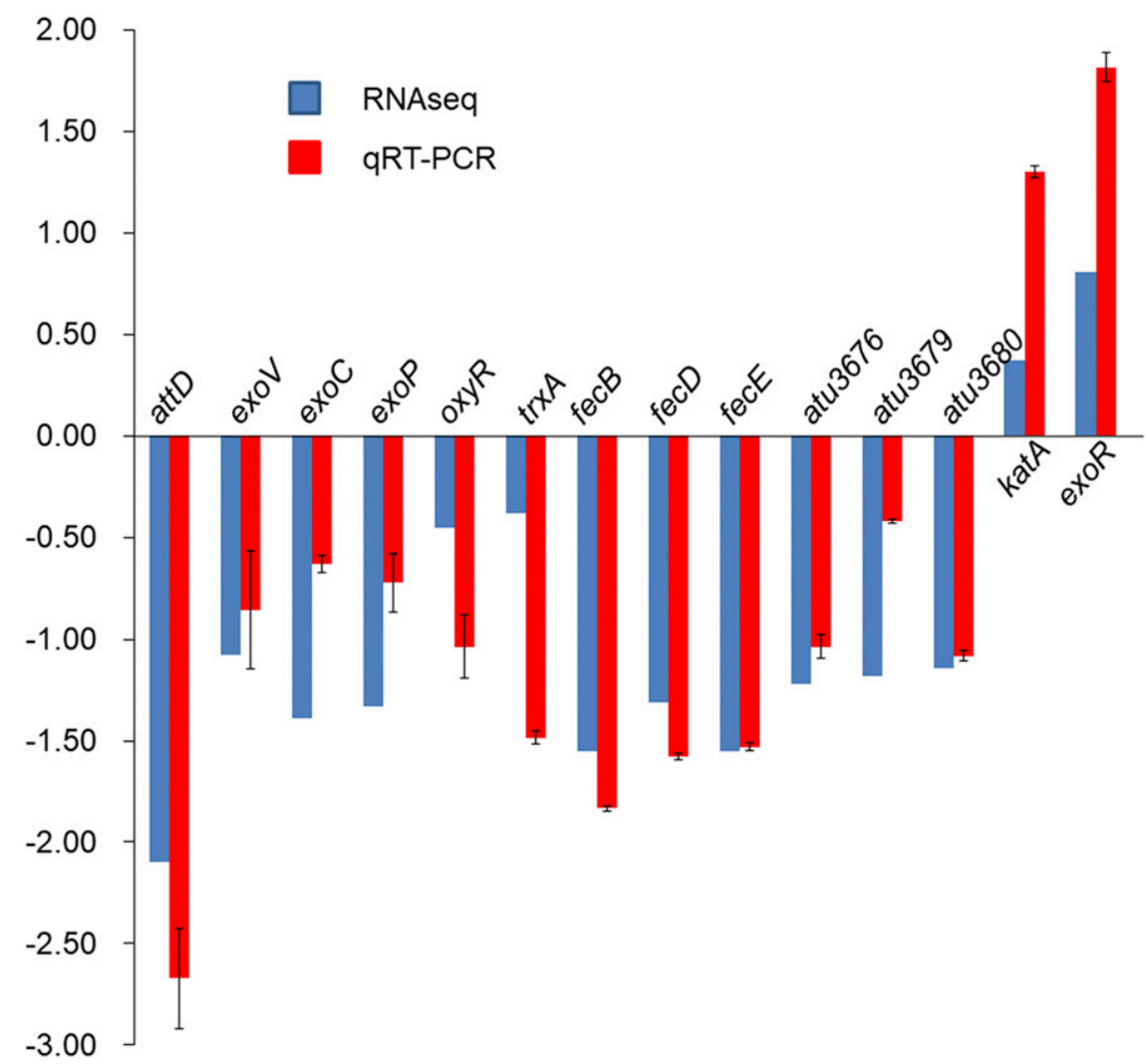

Fig. 8. Differential gene expression in the Agrobacterium tumefaciens $l s r B$ deletion mutant. A. tumefaciens strains were cultured to density at $600 \mathrm{~nm}=0.5$, and total RNA was extracted for RNA-Seq and RT-qPCR. RNA-Seq was performed at Shanghai BoHao Corporation, Shanghai. Transcript levels of indicated genes were determined by RT-qPCR. Vertical bars indicate the standard error for three independent experiments. The relative amount of mRNA for each gene was calculated using the threshold cycle $(\Delta \mathrm{Ct})$ method, normalized to the ropD gene. 
Sample values were normalized using a ropD primer set and were calibrated against the results for wild-type.

\section{Nodulation tests.}

Nodulation assays using alfalfa plants were performed as reported previously (Tang et al. 2013). Briefly, alfalfa seeds were surface-sterilized and were germinated. Alfalfa seedlings were soaked for $30 \mathrm{~min}$ in a diluted bacterial solution $\left(\mathrm{OD}_{600}=\right.$ $0.05)$ and were transferred to pots filled with a mixture of autoclaved vermiculite and perlite (3:1). After inoculation, the number of nodulated plants and the dry weight of shoots were recorded for 4 weeks. The plants were watered with autoclaved nitrogen-free liquid medium every 3 days.

\section{Transient GUS activity assays of Arabidopsis plants.}

Transient Agrobacterium-mediated transformation assays were performed as described by Nam et al. (1999) and Mysore et al. (2000). For transient GUS activity assays (Mestiri et al. 2014), root segments from 10-day-old seedlings grown in vitro were pooled and were cocultivated with A. tumefaciens harboring the binary vector pCAMBIA2301 (Cambia) in hormonefree Murashige and Skoog (MS) medium for $48 \mathrm{~h}$ at $22^{\circ} \mathrm{C}$. Next, the seedlings were washed once in hormone-free MS medium and, then, were cultured in hormone-free MS medium supplemented with timentin for an additional 4 days, to kill the bacteria. Roots were subsequently stained with GUS buffer [100 mM Na $2 \mathrm{HPO}_{4}, 100 \mathrm{mM} \mathrm{KH}{ }_{2} \mathrm{PO}_{4}, 10 \mathrm{mM}$ EDTA, $0.5 \mathrm{mM}$ $\mathrm{K}_{3} \mathrm{Fe}(\mathrm{CN})_{6}, 0.5 \mathrm{mM} \mathrm{K}_{4} \mathrm{Fe}(\mathrm{CN})_{6}, 1 \mathrm{mg} \mathrm{X}$-gluc, $\mathrm{pH}$ 7.0] overnight at $37^{\circ} \mathrm{C}$. The stained samples were rinsed three times with $1 \times$ phosphate-buffered saline and were cleared in different concentrations of ethanol. The number of blue spots per root segment was counted, and three independent experiments were performed.

\section{Plant attachment assays.}

Arabidopsis root-attachment assays were carried out as previously described (Tomlinson et al. 2010), with minor modifications. Roots of 5-day-old Arabidopsis thaliana seedlings grown on MS agar medium were transferred to sterile dishes containing $15 \mathrm{ml}$ of $1 \mathrm{mM} \mathrm{CaCl} 2$ and $0.4 \%$ sucrose. Next, the seedlings were inoculated with an $\mathrm{OD}_{600}=0.01$ of the appropriate derivative strain of $A$. tumefaciens carrying the GFP reporter plasmid pHC60 (Cheng and Walker 1998). Ten root segments were inoculated per strain. After $2 \mathrm{~h}$ of incubation in the dark at room temperature, the root segments were rinsed and were resuspended in fresh calcium chloride and sucrose solution. Five roots were used to count the number of bacteria $\left(\mathrm{CFU} \mathrm{ml} \mathrm{m}^{-1}\right)$, and another five roots were sealed under coverslips. Fluorescence microscopy was performed under a Nikon microscope.

\section{Transient GUS activity assays of tobacco plants.}

A. tumefaciens cells harboring the binary vector pCAMBIA2301 were harvested by centrifugation. The cells were suspended in sterile water to an $\mathrm{OD}_{600}$ of 0.2 , corresponding to approximately $2 \times 10^{7} \mathrm{CFU}$ per milliliter. Half of a leaf (four weeks) was infiltrated with the A. tumefaciens $\mathrm{C} 58 \mathrm{C} 1$ bacterial suspension through the stomata on the abaxial side, using a 1-ml plastic syringe (without a needle). The second half of the leaf was inoculated with the $\Delta l s r B_{a t}$ mutant. After 2 days, the leaves were stained with with X-gluc and NBT buffer.

\section{Surviving bacterial counts.}

To determine bacterial growth in tobacco leaves, wild-type tobacco plants (6 weeks old) were syringe-inoculated with the $\mathrm{C} 58 \mathrm{C} 1$ or the $\Delta l s r B_{a t}$ strain $\left(5 \times 10^{6} \mathrm{CFU} / \mathrm{ml}\right)$. The internal bacterial number was determined at several timepoints (after 0 ,
$1,2,3$, and 4 days postinoculation) via surface-sterilization of a $1-\mathrm{cm}^{2}$ section of inoculated plants with $5 \% \mathrm{H}_{2} \mathrm{O}_{2}$ for $3 \mathrm{~min}$ (Ishiga and Ichinose 2016). After washing three times with $100 \mu \mathrm{l}$ of sterile distilled water, the plants were homogenized in sterile distilled water and the diluted samples were plated on LB medium. Two to three days after plating of the diluted samples, bacterial CFU were counted. Bacterial numbers were evaluated in three independent experiments.

\section{Assay of superoxide anion radicals.}

NBT (Sigma) was used to detect superoxide. Samples were stained with $3.5 \mathrm{mg}$ of NBT per milliliter in $0.1 \mathrm{M}$ potassium phosphate, at $\mathrm{pH} \mathrm{7.0,} \mathrm{and} \mathrm{were} \mathrm{vacuum-infiltrated} \mathrm{three} \mathrm{times}$ (10 min each) in NBT staining solution. After infiltration, leaves were stained for $2 \mathrm{~h}$ at room temperature, followed by a wash with distilled water. The samples were then cleared in $75 \%$ ethanol.

\section{Assay for succinoglycan or EPS levels.}

A. tumefaciens colonies were inoculated into LB liquid medium and were grown overnight at $28^{\circ} \mathrm{C}$ with shaking. The cultures were normalized to an $\mathrm{OD}_{600}$ of 0.2 , and $5 \mu \mathrm{l}$ was spotted onto LB plates supplemented with $0.02 \%$ Calcofluor white M2R (Sigma). The plates were incubated for 2 days at $28^{\circ} \mathrm{C}$, and succinoglycan production was visualized under visible and UV light (Wang et al. 2013; Yao et al. 2004). All strains were imaged using the same exposure value. The fluorescence intensity was analyzed using ImageJ software. Next, $0.25 \mathrm{ml}$ of A. tumefaciens strains, cultured to stationary phase in $\mathrm{LB}$, and $0.75 \mathrm{ml}$ of isopropanol was added to precipitate EPS. The pellet was washed once with $70 \%$ ethanol, was air dried, was redissolved in $0.25 \mathrm{ml}$ of distilled water, and was used for total EPS measurements using the sulfate-anthrone method (Wang et al. 2010).

\section{Biofilm formation.}

Biofilm formation in glass tubes was investigated using the method described by Calatrava-Morales et al. (2017), with modification. Briefly, outgrown cultures of the tested strains were diluted 100-fold in glass tubes containing $4 \mathrm{ml}$ of fresh LB broth. The tubes were incubated for $48 \mathrm{~h}$ at $28^{\circ} \mathrm{C}$, under shaking conditions, for quantification of biofilm levels. After incubation, liquid from the tubes was removed and the bacterial biofilms were stained with $4 \mathrm{ml}$ of $0.1 \%$ crystal violet solution (Sigma-Aldrich) for $20 \mathrm{~min}$. The tubes were carefully washed three times with deionized water to eliminate excess crystal violet. The crystal violet was solubilized by the addition of $2 \mathrm{ml}$ of acetic acid (30\% vol/vol), and absorbance at $590 \mathrm{~nm}$ was used for quantification of the solubilized crystal violet stain.

\section{Assay of oxidative stress sensitivity.}

The sensitivity of A. tumefaciens to SNP was examined by growing cells in $\mathrm{LB}$ medium at $28^{\circ} \mathrm{C}$, with shaking at $200 \mathrm{rpm} / \mathrm{min}$, to $\mathrm{OD}_{600}=0.5$, followed by centrifugation. The cultures were serially diluted tenfold in LB broth, and aliquots $(5 \mu \mathrm{l})$ were spotted onto LB agar supplemented with $10 \mathrm{mM}$ $\mathrm{H}_{2} \mathrm{O}_{2}$ or $10 \mathrm{mM} \mathrm{SNP}$, to determine the oxidative resistance of the strains at $28^{\circ} \mathrm{C}$ for 4 days.

\section{Sensitivity to Dipy.}

Overnight cultures grown in TY medium were washed once with fresh TY medium; the cells were diluted to an $\mathrm{OD}_{600}$ of 0.05 , and an iron-limiting condition was achieved by adding $0.1 \mathrm{mM}$ concentration of the iron chelator 2,2-dipyridyl (Dipy; Sigma). Growth was monitored by measuring the $\mathrm{OD}_{600}$ after incubation at $28^{\circ} \mathrm{C}$, with shaking, for $36 \mathrm{~h}$. The effect of the addition of metal ions on bacterial growth in the presence of 
Dipy was assayed on TY agar plates. Overnight cultures grown in TY medium were washed and were adjusted to an $\mathrm{OD}_{600}$ of 0.03 in TY medium. Tenfold serial dilutions were made. An aliquot $(5 \mu \mathrm{l})$ of each dilution was spotted onto TY agar plates containing $0.2 \mathrm{mM}$ Dipy and $0.1 \mathrm{mM}$ of $\mathrm{FeCl}_{3}$ and then incubated at $28^{\circ} \mathrm{C}$ for 4 days. Cells spotted onto a TY agar plate were used as a control.

\section{Growth curves.}

Bacteria were cultured in LB broth, and cells in the exponential growth phase were diluted in fresh medium to $\mathrm{OD}_{600}=$ 0.05 . The cell density $\left(\mathrm{OD}_{600}\right)$ was monitored at each timepoint.

\section{DNA sequence analysis.}

The deduced protein sequence of LsrB was downloaded from the Sinorhizobium meliloti genome site. Homologs of LsrB were aligned and downloaded from the National Center for Biotechnology Information Blast Microbial Genomes website.

\section{ACKNOWLEDGMENTS}

We thank S. Yu for the gift of B. abortus 2308 genomic DNA.

\section{LITERATURE CITED}

Azpiroz-Leehan, R., and Feldmann, K. A. 1997. T-DNA insertion mutagenesis in Arabidopsis: Going back and forth. Trends Genet. 13: $152-156$.

Baker, C. J., and Orlandi, E. W. 1995. Active oxygen in plant pathogenesis. Annu. Rev. Phytopathol. 33:299-321.

Beringer, J. E. 1974. R factor transfer in Rhizobium leguminosarum. J. Gen. Microbiol. 84:188-198.

Bhattacharya, A., Sood, P., and Citovsky, V. 2010. The roles of plant phenolics in defence and communication during Agrobacterium and Rhizobium infection. Mol. Plant Pathol. 11:705-719.

Brencic, A., and Winans, S. C. 2005. Detection of and response to signals involved in host-microbe interactions by plant-associated bacteria. Microbiol. Mol. Biol. Rev. 69:155-194.

Calatrava-Morales, N., Nogales, J., Ameztoy, K., van Steenbergen, B., and Soto, M. J. 2017. The NtrY/NtrX System of Sinorhizobium meliloti GR4 Regulates Motility, EPS I Production, and Nitrogen Metabolism but Is Dispensable for Symbiotic Nitrogen Fixation. Mol. Plant-Microbe Interact. 30:566-577.

Chen, E. J., Sabio, E. A., and Long, S. R. 2008. The periplasmic regulator ExoR inhibits ExoS/ChvI two-component signalling in Sinorhizobium meliloti. Mol. Microbiol. 69:1290-1303.

Cheng, H. P., and Walker, G. C. 1998. Succinoglycan is required for initiation and elongation of infection threads during nodulation of alfalfa by Rhizobium meliloti. J. Bacteriol. 180:5183-5191.

Finan, T. M., Hartweig, E., LeMieux, K., Bergman, K., Walker, G. C., and Signer, E. R. 1984. General transduction in Rhizobium meliloti. J. Bacteriol. 159:120-124.

Foulongne, V., Bourg, G., Cazevieille, C., Michaux-Charachon, S., and O'Callaghan, D. 2000. Identification of Brucella suis genes affecting intracellular survival in an in vitro human macrophage infection model by signature-tagged transposon mutagenesis. Infect. Immun. 68:1297-1303.

Franza, T., Sauvage, C., and Expert, D. 1999. Iron regulation and pathogenicity in Erwinia chrysanthemi 3937: Role of the Fur repressor protein. Mol. Plant-Microbe Interact. 12:119-128.

Goodner, B., Hinkle, G., Gattung, S., Miller, N., Blanchard, M., Qurollo, B. Goldman, B. S., Cao, Y., Askenazi, M., Halling, C., Mullin, L., Houmiel, K., Gordon, J., Vaudin, M., Iartchouk, O., Epp, A., Liu, F., Wollam, C., Allinger, M., Doughty, D., Scott, C., Lappas, C., Markelz, B., Flanagan, C., Crowell, C., Gurson, J., Lomo, C., Sear, C., Strub, G., Cielo, C., and Slater, S. 2001. Genome sequence of the plant pathogen and biotechnology agent Agrobacterium tumefaciens C58. Science 294:2323-2328.

Hynes, M. F., Simon, R., and Pühler, A. 1985. The development of plasmidfree strains of Agrobacterium tumefaciens by using incompatibility with a Rhizobium meliloti plasmid to eliminate pAtC58. Plasmid 13:99-105.

Imlay, J. A., Chin, S. M., and Linn, S. 1988. Toxic DNA damage by hydrogen peroxide through the Fenton reaction in vivo and in vitro. Science 240:640-642.
Ishiga, Y., and Ichinose, Y. 2016. Pseudomonas syringae pv. tomato OxyR is required for virulence in tomato and Arabidopsis. Mol. Plant-Microbe Interact. 29:119-131.

Jamet, A., Kiss, E., Batut, J., Puppo, A., and Hérouart, D. 2005. The katA catalase gene is regulated by OxyR in both free-living and symbiotic Sinorhizobium meliloti. J. Bacteriol. 187:376-381.

Jelenic, S., Mitrikeski, P.T., Papes, D., and Jelaska, S. 2000 Agrobacteriummediated transformation of broad bean Vicia faba L. Food Technol. Biotech. 38:167-172

Khan, S. R., Gaines, J., Roop, R. M., 2nd, and Farrand, S. K. 2008. Broadhost-range expression vectors with tightly regulated promoters and their use to examine the influence of TraR and TraM expression on Ti plasmid quorum sensing. Appl. Environ. Microbiol. 74:5053-5062.

Lacroix, B., and Citovsky, V. 2013. The roles of bacterial and host plant factors in Agrobacterium-mediated genetic transformation. Int. J. Dev. Biol. 57:467-481.

Lippincott, B. B., and Lippincott, J. A. 1969. Bacterial attachment to a specific wound site as an essential stage in tumor initiation by Agrobacterium tumefaciens. J. Bacteriol. 97:620-628.

Lu, D., Tang, G., Wang, D., and Luo, L. 2013. The Sinorhizobium meliloti LysR family transcriptional factor LsrB is involved in regulation of glutathione biosynthesis. Acta Biochim. Biophys. Sin. (Shanghai) 45: 882-888.

Luo, L., Yao, S. Y., Becker, A., Rüberg, S., Yu, G. Q., Zhu, J. B., and Cheng, H. P. 2005. Two new Sinorhizobium meliloti LysR-type transcriptional regulators required for nodulation. J. Bacteriol. 187:4562-4572.

Maddocks, S. E., and Oyston, P. C. 2008. Structure and function of the LysR-type transcriptional regulator (LTTR) family proteins. Microbiology 154:3609-3623.

Matthysse, A. G., Yarnall, H., Boles, S. B., and McMahan, S. 2000. A region of the Agrobacterium tumefaciens chromosome containing genes required for virulence and attachment to host cells. Biochim. Biophys. Acta 1490:208-212.

Mestiri, I., Norre, F., Gallego, M. E., and White, C. I. 2014. Multiple hostcell recombination pathways act in Agrobacterium-mediated transformation of plant cells. Plant J. 77:511-520.

Mila, I., Scalbert, A., and Expert, D. 1996. Iron withholding by plant polyphenols and resistance to pathogens and rots. Phytochemistry 42: 1551-1555.

Mysore, K. S., Kumar, C. T., and Gelvin, S. B. 2000. Arabidopsis ecotypes and mutants that are recalcitrant to Agrobacterium root transformation are susceptible to germ-line transformation. Plant J. 21:9-16.

Nair, G. R., Liu, Z., and Binns, A. N. 2003. Reexamining the role of the accessory plasmid pAtC58 in the virulence of Agrobacterium tumefaciens strain C58. Plant Physiol. 133:989-999.

Nakjarung, K., Mongkolsuk, S., and Vattanaviboon, P. 2003. The oxyR from Agrobacterium tumefaciens: Evaluation of its role in the regulation of catalase and peroxide responses. Biochem. Bioph. Res. Co. 304:41-47.

Nam, J., Mysore, K. S., Zheng, C., Knue, M. K., Matthysse, A. G., and Gelvin, S. B. 1999. Identification of T-DNA tagged Arabidopsis mutants that are resistant to transformation by Agrobacterium. Mol. Gen. Genet 261:429-438.

Neema, C., Laulhere, J. P., and Expert, D. 1993. Iron deficiency induced by chrysobactin in Saintpaulia leaves inoculated with Erwinia chrysanthemi. Plant Physiol. 102:967-973.

Oka-Kira, E., and Kawaguchi, M. 2006. Long-distance signaling to control root nodule number. Curr. Opin. Plant Biol. 9:496-502.

Palmer, A. G., Gao, R., Maresh, J., Erbil, W. K., and Lynn, D. G. 2004 Chemical biology of multi-host/pathogen interactions: Chemical perception and metabolic complementation. Annu. Rev. Phytopathol. 42: 439-464.

Pitzschke, A., and Hirt, H. 2010. New insights into an old story: Agrobacteriuminduced tumour formation in plants by plant transformation. EMBO J. 29:1021-1032.

Saenkham, P., Eiamphungporn, W., Farrand, S. K., Vattanaviboon, P., and Mongkolsuk, S. 2007. Multiple superoxide dismutases in Agrobacterium tumefaciens: Functional analysis, gene regulation, and influence on tumorigenesis. J. Bacteriol. 189:8807-8817.

Sambrook, J., Fritsch, E. F., and Maniatis, T. 1989. Molecular cloning, 2nd Ed. Cold Spring Harbor Laboratory Press, Cold Spring Harbor, NY.

Schäfer, A., Tauch, A., Jäger, W., Kalinowski, J., Thierbach, G., and Pühler, A. 1994. Small mobilizable multi-purpose cloning vectors derived from the Escherichia coli plasmids pK18 and pK19: Selection of defined deletions in the chromosome of Corynebacterium glutamicum. Gene 145:69-73.

Schell, M. A. 1993. Molecular biology of the LysR family of transcriptional regulators. Annu. Rev. Microbiol. 47:597-626. 
Sheehan, L. M., Budnick, J. A., Blanchard, C., Dunman, P. M., and Caswell, C. C. 2015. A LysR-family transcriptional regulator required for virulence in Brucella abortus is highly conserved among the $\alpha$-proteobacteria. Mol. Microbiol. 98:318-328.

Shimoda, N., Toyoda-Yamamoto, A., Nagamine, J., Usami, S., Katayama, M., Sakagami, Y., and Machida, Y. 1990. Control of expression of Agrobacterium vir genes by synergistic actions of phenolic signal molecules and monosaccharides. Proc. Natl. Acad. Sci. U.S.A. 87:6684-6688.

Subramoni, S., and Sonti, R. V. 2005. Growth deficiency of a Xanthomonas oryzae pv. oryzae fur mutant in rice leaves is rescued by ascorbic acid supplementation. Mol. Plant-Microbe Interact. 18:644-651.

Tang, G., Wang, Y., and Luo, L. 2014. Transcriptional regulator LsrB of Sinorhizobium meliloti positively regulates the expression of genes involved in lipopolysaccharide biosynthesis. Appl. Environ. Microbiol. 80:5265-5273.

Tang, G., Xing, S., Wang, S., Yu, L., Li, X., Staehelin, C., Yang, M., and Luo, L. 2017. Regulation of cysteine residues in LsrB proteins from Sinorhizobium meliloti under free-living and symbiotic oxidative stress. Environ. Microbiol. 19:5130-5145.

Tang, G. R., Lu, D. W., Wang, D., and Luo, L. 2013. Sinorhizobium meliloti lsrB is involved in alfalfa root nodule development and nitrogen-fixing bacteroid differentiation. Chin. Sci. Bull. 58:4077-4083.

Thomashow, L. S., Reeves, S., and Thomashow, M. F. 1984. Crown gall oncogenesis: Evidence that a T-DNA gene from the Agrobacterium Ti plasmid pTiA6 encodes an enzyme that catalyzes synthesis of indoleacetic acid. Proc. Natl. Acad. Sci. U.S.A. 81:5071-5075.

Tomlinson, A. D., Ramey-Hartung, B., Day, T. W., Merritt, P. M., and Fuqua, C. 2010. Agrobacterium tumefaciens ExoR represses succinoglycan biosynthesis and is required for biofilm formation and motility. Microbiology 156:2670-2681.

Wang, D., Xue, H., Wang, Y., Yin, R., Xie, F., and Luo, L. 2013. The Sinorhizobium meliloti ntrX gene is involved in succinoglycan production, motility, and symbiotic nodulation on alfalfa. Appl. Environ. Microbiol. 79:7150-7159.

Wang, Y., Xu, J., Chen, A., Wang, Y., Zhu, J., Yu, G., Xu, L., and Luo, L. 2010. GGDEF and EAL proteins play different roles in the control of Sinorhizobium meliloti growth, motility, exopolysaccharide production, and competitive nodulation on host alfalfa. Acta Biochim. Biophys. Sin. (Shanghai) 42:410-417.
Wells, D. H., Chen, E. J., Fisher, R. F., and Long, S. R. 2007. ExoR is genetically coupled to the ExoS-ChvI two-component system and located in the periplasm of Sinorhizobium meliloti. Mol. Microbiol. 64: 647-664.

White, P. R., and Braun, A. C. 1941. Crown gall production by bacteria-free tumor tissues. Science 94:239-241.

Wood, D. W., Setubal, J. C., Kaul, R., Monks, D. E., Kitajima, J. P., Okura, V. K., Zhou, Y., Chen, L., Wood, G. E., Almeida, N. F., Jr., Woo, L., Chen, Y., Paulsen, I. T., Eisen, J. A., Karp, P. D., Bovee, D., Sr., Chapman, P., Clendenning, J., Deatherage, G., Gillet, W., Grant, C., Kutyavin, T., Levy, R., Li, M. J., McClelland, E., Palmieri, A., Raymond, C., Rouse, G., Saenphimmachak, C., Wu, Z., Romero, P., Gordon, D., Zhang, S., Yoo, H., Tao, Y., Biddle, P., Jung, M., Krespan, W., Perry, M., Gordon-Kamm, B., Liao, L., Kim, S., Hendrick, C., Zhao, Z. Y., Dolan, M., Chumley, F., Tingey, S. V., Tomb, J. F., Gordon, M. P., Olson, M. V., and Nester, E. W. 2001. The genome of the natural genetic engineer Agrobacterium tumefaciens C58. Science 294:2317-2323.

Wu, C. F., Lin, J. S., Shaw, G. C., and Lai, E. M. 2012. Acid-induced type VI secretion system is regulated by ExoR-ChvG/ChvI signaling cascade in Agrobacterium tumefaciens. PLoS Pathog. 8:e1002938.

$\mathrm{Xu}, \mathrm{X}$. Q., Li, L. P., and Pan, S. Q. 2008. Feedback regulation of an Agrobacterium catalase gene katA involved in Agrobacterium-plant interaction. Mol. Microbiol. 42:645-657.

Xu, X. Q., and Pan, S. Q. 2000. An Agrobacterium catalase is a virulence factor involved in tumorigenesis. Mol. Microbiol. 35:407-414.

Yao, S. Y., Luo, L., Har, K. J., Becker, A., Rüberg, S., Yu, G. Q., Zhu, J. B., and Cheng, H. P. 2004. Sinorhizobium meliloti ExoR and ExoS proteins regulate both succinoglycan and flagellum production. J. Bacteriol. 186: 6042-6049.

\section{AUTHOR-RECOMMENDED INTERNET RESOURCES}

The Sinorhizobium meliloti genome site: http://iant.Toulouse.inra.fr/bacteria/annotation/cgi/rhime.cgi

National Center for Biotechnology Information Blast Microbial Genomes website: https://blast.ncbi.nlm.nih.gov/Blast.cgi?PAGE_TYPE=BlastSearch \&BLAST_SPEC=MicrobialGenomes 